\title{
Cadmium contamination of drinking water and its treatment using biological chelators
}

\author{
Amiri $\mathrm{A}, \mathrm{PhD}^{1 *}$, Mirhoseiny $\mathrm{Z}, \mathrm{Msc}^{2}$ \\ 1- Assistant Prof., Dept. of Chemistry, Payame Noor University, P.O. Box, 19395-3697, Tehran, Iran. 2- MSc in Chemistry, \\ Department of Chemistry, Payame Noor University, P.O. Box, 19395-3697, Tehran, Iran
}

\begin{abstract}
Received: July 2016, Accepted: October 2016

Background: Cadmium $(\mathrm{Cd})$ is an extremely toxic metal and environmental exposure to $\mathrm{Cd}$ has been particularly problematic in the world. Oral exposure to $\mathrm{Cd}$ may result in adverse effects on a number of tissues, the immune system, and the cardiovascular system. Compounds containing $\mathrm{Cd}$ are also carcinogenic. The presence of $\mathrm{Cd}$ in drinking water resources in the southeastern region of Rafsanjan plain (Iran) at concentrations greater than acceptable limits may result in various adverse health effects. The aim of this research was to test the chelation potency of deferasirox (DFS or ICL670), a tridentate metal chelator, and deferiprone $\left(\mathrm{L}_{1}\right)$, a bidentate metal chelator, in the mobilization of $\mathrm{Cd}$ in Cd-exposed rats as a biological model.

Materials and Methods: Male Wistar rats were exposed to $40 \mathrm{mg} / \mathrm{kg}$ body weight of cadmium chloride in drinking water for 6 weeks, followed by treatment with DFS $(100 \mathrm{mg} / \mathrm{kg}$ body weight, oral, once daily) and $\mathrm{L}_{1}(100 \mathrm{mg} / \mathrm{kg}$ body weight, oral, once daily), alone or in combination, for 7 consecutive days. After chelation therapy, the rats were anesthetized by ether vapor and immobilized by cervical dislocation. Then, their heart, liver, kidneys, intestine, and blood were sampled for clinical hematological variables and determination of $\mathrm{Cd}$ and $\mathrm{Fe}$ concentration by inductively coupled plasma optical emission spectrometry (ICP-OES). The data were subjected to statistical analysis using Student's t-test. All $\mathrm{P}$ values of less than 0.05 were considered significant.

Results: The results show that both chelators (DFS and $\mathrm{L}_{1}$ ) increase the removal of $\mathrm{Cd}$ from the tissues. No effects of $\mathrm{Cd}$ or any of the two treatments ( $\mathrm{L}_{1}$ or DFS) were observed on white blood cell (WBC) count, red blood cell (RBC) count, and hemoglobin (Hb) level.

Conclusions: The comparison of single and combined therapy showed that the combined chelation therapy $\left(\mathrm{DFS}+\mathrm{L}_{1}\right)$ was more effective in depleting Cd concentration in soft tissues.
\end{abstract}

Keywords: Chelation Therapy, Cadmium, Drinking Water, Rats

\section{Introduction}

Cadmium is a toxic metalloid widely present around the world particularly in soil, water, or contaminated food. Cd is primarily used in metal plating and coating operations, including transportation equipment, machinery and baking enamels, photography, and television phosphors. It is also used in nickel-cadmium and solar batteries, and in pigments (1). Cd is regularly found in ores together with zinc, copper, and lead. Therefore, volcanic activity is one natural reason for a temporary increase in environmental $\mathrm{Cd}$ concentrations. Phosphate fertilizers also show a high $\mathrm{Cd}$ load. Acute exposure to $\mathrm{Cd}$ fumes may cause flu- like symptoms including chills, fever, and muscle ache sometimes referred to as "the cadmium blues". Symptoms may resolve after a week if there is no respiratory damage. More severe exposures can cause tracheobronchitis, pneumonitis, and pulmonary edema. Symptoms of inflammation may start hours after the exposure and include coughs, dryness and irritation of the nose and throat, headache, dizziness, weakness, fever, chills, and chest pain. Ingestion of any significant amount of Cd causes immediate poisoning and

\footnotetext{
* Corresponding author: Asghar Amiri, Dept. of Chemistry, Payame Noor University, P.O. Box, 193953697, Tehran, Iran.

Email: a.amiri@pnu.ac.ir
} 
damage to the liver and the kidneys. The bones become soft (osteomalacia), lose bone mineral density (osteoporosis), and become weaker. This causes pain in the joints and back and also increases the risk of fractures $(2,3)$.

The concentrations of $\mathrm{Cd}$ in drinking water supplies of villages located in the southeastern region of Rafsanjan plain (Iran) exceed the standard limit permitted by the World Health Organization (WHO) guidelines $(0.010 \mathrm{mg} / \mathrm{l})$. About $10.4 \%$ of residents of this area were exposed to arsenic. Furthermore, the results revealed that $66.6 \%$ and $46.7 \%$ of the residents of the study area had, respectively, been exposed to high levels of lead and $\mathrm{Cd}$. The heavy metals, such as $\mathrm{Cd}$, contamination of drinking water resources in Rafsanjan plain is linked to both natural presence of sulfide veins in this area and manmade pollution due to the presence of the main road and agricultural use of pesticides $(4,5)$.

Detoxification of $\mathrm{Cd}$ is possible with ethylenediaminetetraacetic acid (EDTA) and other chelators and has been shown to be therapeutically beneficial in humans and animals when done using the established protocols. It is clear that EDTA and meso 2, 3dimercaptosuccinic acid (DMSA) increase urinary excretion of $\mathrm{Cd}$. In clinical use, EDTA is credited with an anecdotal report of rheumatoid arthritis relief, reduction of oxidative stress, and reduction of general metal toxicity. Subsequent human trials in West Bengal (India) with DMSA failed to provide clinical recoveries in patients chronically exposed to arsenic and some heavy metals (6-10). Clinical investigations of the use of some chelators for the removal of toxic metals in rats have been previously published $(11,12)$.

Deferasirox $\quad$ 44-[3,5-bis(2-hydroxyphenyl)1,2,4-triazol-1-yl]-benzoic acid (ICL670 or DFS) \} (Figure 1) is a tridentate chelator with high selectivity for $\mathrm{Fe}^{3+}$. In 2005, DFS became the first Food and Drug Administration (FDA) approved oral alternative for treatment of $\mathrm{Fe}$ overload, and subsequently, was approved in the EU in 2006 (8). Its comparatively long half-life before excretion allows a once-daily dosage and good overall patient compliance, as well as cost-effectiveness. DFS possesses a $\mathrm{pFe}^{3+}$ value of 22.5 , can penetrate membranes easily, and possesses good oral availability. Indeed, when orally administered to hypertransfused rats, DFS promotes the excretion of chelatable iron from hepatocellular iron stores four to five times more effectively than desferrioxamine (13). Another developed orally active chelating agent is deferiprone (1,2-dimethyl-3hydroxypyrid-4-one or $\mathrm{L}_{1}$ ), which is rapidly absorbed in the gastrointestinal tract and normally appears in serum a few minutes after oral administration. The main excretion route is the kidneys. $\mathrm{L}_{1}$ is a bidentate iron chelator forming a 3:1 complex with Fe and it is likely to act intracellular $(14,15)$. The presence of $\mathrm{Cd}$ in drinking water resources of Rafsanjan plain at concentrations greater than acceptable limits may result in various adverse health effects. The therapeutic efficacy of DFS and $\mathrm{L}_{1}$ in reducing $\mathrm{Cd}$ concentration in Cd-exposed rats as a biological model was investigated in the present study.

\section{Material and Methods}

All the chemicals used in this work were of either analytical grade or of extra pure grade of the highest purity available locally. Cadmium chloride, deferiprone, and other materials were purchased from Merck Chemicals Co. (Germany) and deferasirox was purchased from Novartis Co. (Basel. Switzerland). Male Wistar rats were obtained from the animal house facility of Kerman Neuroscience Research Center (Iran). The animals were kept under a controlled light/dark (12/12 hours) schedule. The rats were divided randomly into control and experimental groups. They were treated in groups and were housed in wellcleaned sterilized cages in an air-conditioned room with the temperature maintained at $22 \pm$ $2{ }^{\circ} \mathrm{C}$ and $50 \%$ humidity. The Animal Ethical Committee of Payame Noor University and 
Kerman Neuroscience Research Center approved the protocols for the experiments.

Experimental Groups: In order to evaluate the efficacy of chelators (DFS and $\mathrm{L}_{1}$ ) in removing $\mathrm{Cd}$ in $\mathrm{Cd}$-exposed rats, experiments were performed on Wistar male rats $(220 \pm 12$ g). The animals were classified into 2 groups. The control group $(n=5)$ was given normal food and distilled water to drink. The concentrations of $\mathrm{Cd}$ and $\mathrm{Fe}$ in the control group rats were compared with the groups that received $\mathrm{Cd}$ and chelators. The toxic groups ( $\mathrm{n}$ = 25) were given water containing $40 \mathrm{mg} / \mathrm{kg}$ body weight $\mathrm{Cd}^{2+}$ as cadmium chloride for 42 days. In order to compare the $\mathrm{Cd}$ and $\mathrm{Fe}$ concentrations in tissues, before and after chelation therapy, one group was selected (Vehicle $\mathrm{Cd}$ and Vehicle $\mathrm{Fe}$ ) and sacrificed before chelation therapy. Other Cd-exposed animals were divided into 4 sub-groups of 5 rats each and given the following treatment for 7 consecutive days:

- Group control chelator (No treatment)

- Group $\mathrm{L}_{1}(100 \mathrm{mg} / \mathrm{kg}$ body weight, oral, once daily)

- Group DFS (100 mg/kg body weight, oral, once daily)

- Group DFS+L ${ }_{1}$ (50 and $50 \mathrm{mg} / \mathrm{kg}$ body weight, respectively, oral, once daily)

All animals of each group were sacrificed under light ether anesthesia, 48 hours after the last dosing. Kidneys, heart, liver, and intestine samples were weighed, dried, and collected for determination of $\mathrm{Cd}$ and $\mathrm{Fe}$ concentration. The samples were placed in an oven at $60{ }^{\circ} \mathrm{C}$ for 3 days. Then, $1 \mathrm{~g}$ of each sample was digested by $1 \mathrm{ml}$ of $\mathrm{HNO}_{3}(10 \mathrm{M})$. After digestion, the solutions were vaporized with the addition of $0.5 \mathrm{ml}$ of $\mathrm{H}_{2} \mathrm{O}_{2} \quad(30 \%)$ under a hood. Subsequently, the fragments were diluted with distilled water to $10 \mathrm{ml}$ volume. Determination of $\mathrm{Cd}$ and $\mathrm{Fe}$ in samples was performed using inductively coupled plasma optical emission spectrometry (ICP-OES) (Vista-MPX, Varian Inc., CA, USA). The values are expressed as mean values (at least three separate determinations) \pm standard error of the mean (SEM). The data were subjected to statistical analysis using Student's t-test. All P values of less than 0.05 were considered significant.

Clinical hematological variables: Blood was collected through cardiac puncture in heparinized tubes and the hemoglobin $(\mathrm{Hb})$ level, platelet (PLT) count, red blood cell (RBC) count, and white blood cell (WBC) count were measured using a hematology analyzer (model K4500, Sysmex Corp., Kobe, Japan).

\section{Results}

Oral exposure to $\mathrm{Cd}$ may result in adverse effects on a number of tissues, including kidney, liver, bone, testes, the immune system, and the cardiovascular system. In humans, death is usually due to excessive fluid loss as a result of vomiting and diarrhea. Lethal doses in humans have been reported to range from 1,500 to $8,900 \mathrm{mg}$, corresponding to doses of about 20 to $130 \mathrm{mg} / \mathrm{kg}$ in a $70 \mathrm{~kg}$ adult (16). The effects of DFS and $\mathrm{L}_{1}$ chelators on $\mathrm{Cd}$ concentration in various tissues are presented in table 1.

Table 1: Concentration of cadmium $(\mathrm{mg} / \mathrm{kg})$ in cadmium-intoxicated rats before and after chelation therapy

\begin{tabular}{cccccc}
\hline Group & Control & Vehicle Cd & DFS & $\mathrm{L}_{1}$ & $\mathrm{DFS}^{+} \mathrm{L}_{1}$ \\
\hline Heart & $0.12 \pm 0.01$ & $6.31 \pm 0.32^{*}$ & $4.52 \pm 0.37^{\dagger}$ & $5.04 \pm 0.12^{*}$ & $4.02 \pm 0.19^{\dagger}$ \\
\hline Kidney & $0.72 \pm 0.05$ & $42.31 \pm 0.21^{*}$ & $9.06 \pm 0.24^{*}$ & $8.01 \pm 0.32^{\dagger}$ & $7.07 \pm 0.24^{\dagger}$ \\
\hline Liver & $0.55 \pm 0.02$ & $15.11 \pm 0.32^{*}$ & $6.62 \pm 0.34^{*}$ & $7.02 \pm 0.29^{\dagger}$ & $4.12 \pm 0.25^{\dagger}$ \\
\hline Intestine & $0.32 \pm 0.01$ & $6.96 \pm 0.03^{*}$ & $4.21 \pm 0.32^{\dagger}$ & $5.97 \pm 0.23$ & $3.01 \pm 0.19^{\dagger}$ \\
\hline
\end{tabular}

Values are presented as mean \pm SEM $(n=5)$; ${ }^{*}$ Significant at $\mathrm{P}<0.05$ when compared with control; ${ }^{\dagger}$ Significant at $\mathrm{P}<0.05$ when compared with vehicle $\mathrm{Cd}$ 
Table 2: Concentration of iron $(\mathrm{mg} / \mathrm{kg})$ in cadmium-intoxicated rats before and after chelation therapy

\begin{tabular}{cccccc}
\hline Group & Control & Vehicle Fe & DFS & $\mathrm{L}_{1}$ & $\mathrm{DFS}^{2} \mathrm{~L}_{1}$ \\
\hline Heart & $5.02 \pm 0.42$ & $4.76 \pm 0.21$ & $4.13 \pm 0.29$ & $3.06 \pm 0.27^{*}$ & $3.01 \pm 0.13^{*}$ \\
\hline Kidney & $7.51 \pm 0.23$ & $5.85 \pm 0.34^{*}$ & $6.01 \pm 0.39$ & $6.12 \pm 0.29$ & $5.12 \pm 0.22^{*}$ \\
\hline Liver & $9.03 \pm 0.31$ & $6.98 \pm 0.27^{*}$ & $5.21 \pm 0.31^{*}$ & $4.12 \pm 0.21^{*}$ & $3.01 \pm 0.21^{*}$ \\
\hline Intestine & $5.02 \pm 0.24$ & $4.16 \pm 0.33$ & $4.03 \pm 0.22$ & $4.01 \pm 0.20$ & $4.01 \pm 0.23$ \\
\hline
\end{tabular}

Values are presented as mean \pm SEM $(n=5)$; *Significant at $\mathrm{P}<0.05$ when compared with control

The maximum amount of $\mathrm{Cd}$ accumulation was observed in the kidneys and liver, respectively. In order to investigate the spontaneous elimination of $\mathrm{Cd}$ from the body by the biological system, the control chelator group was treated without chelation therapy and the removal of $\mathrm{Cd}$ by the biological system in this group was not noticeable. After the chelation therapy, the obtained results indicated that $\mathrm{Cd}$ concentration had significantly reduced in all tissues. There was a statistical difference between DFS and $\mathrm{L}_{1}$ in reducing the amount of $\mathrm{Cd}$ in various tissues. As single therapy efficiencies of chelators were compared in this study, it was found that
DFS was more effective in decreasing Cd level in all tissues, whereas $\mathrm{L}_{1}$ was more effective in reducing $\mathrm{Cd}$ level in the kidneys. The results of Fe concentrations before and after chelation therapy are provided in table 2 .

Fe concentration had significantly decreased after the chelation therapy. Thus, consumption of $\mathrm{Fe}$ tablets is recommended for returning the Fe level to its normal state. Combination of DFS $+\mathrm{L}_{1}$ shows more efficiency in decreasing $\mathrm{Fe}$ level. The effects of exposure to $\mathrm{Cd}$ and treatment with chelators either individually or in combination on some hematological variables are shown in table 3 .

Table 3: Hematological variables in the blood of cadmium-intoxicated rats before and after chelation therapy

\begin{tabular}{cccccc}
\hline Group & Control & Vehicle Cd & DFS & $\mathrm{L}_{1}$ & $\mathrm{DFS}_{+} \mathrm{L}_{1}$ \\
\hline WBC & $12.01 \pm 2.11$ & $12.01 \pm 3.12$ & $15.44 \pm 2.21$ & $10.11 \pm 1.10$ & $11.61 \pm 1.29$ \\
\hline RBC & $8.22 \pm 0.54$ & $9.08 \pm 0.11$ & $8.55 \pm 0.21$ & $8.51 \pm 0.12$ & $8.65 \pm 0.34$ \\
\hline Hb & $133.7 \pm 11.4$ & $120.7 \pm 3$ & $126.7 \pm 1.3$ & $121.5 \pm 6$ & $122.2 \pm 4.5$ \\
\hline PLT & $679.6 \pm 55.5$ & $260.7 \pm 88.7$ & $553.6 \pm 101.1^{*}$ & $221.7 \pm 98.1$ & $701.7 \pm 56.4^{*}$ \\
\hline
\end{tabular}

WBC: White blood cell count as $\times 10^{3} / \mu \mathrm{l}$; RBC: Red blood cell count as $\times 10^{6} / \mu \mathrm{l} ; \mathrm{Hb}$ : Hemoglobin as g/l; PLT: Platelet as $\times 10^{3} / \mu 1$; Values are presented as mean $\pm \operatorname{SEM}(\mathrm{n}=5)$; ${ }^{*}$ Significant at $\mathrm{P}<0.05$ when compared with vehicle $\mathrm{Cd}$

\section{Discussion}

Through the survey of corrosion indexes, it was recognized that drinking water from wells and aqueducts in rural areas adjacent to Rafsanjan plain has scaling tendency. Thus, it is necessary to stop economical loss and hygienic harms in order to maintain water quality stabilization. Water corrosion leads to increase in toxic metals concentration, such as arsenic, copper, lead, Cd, zinc, nickel, iron, and manganese in water. Toxic metals have acute health risks for water consumers. Scaling water leads to economic and technical problems (16). After absorption, $\mathrm{Cd}$ is transported throughout the body, usually bound to a sulfhydryl group-containing protein like metallothionein. About 30\% deposits in the liver and $30 \%$ in the kidneys, with the rest distributed throughout the body. The half-life of $\mathrm{Cd}$ in the blood has been estimated at 75 to 128 days (16). It was found that as $\mathrm{Cd}$ concentration increased in tissues, $\mathrm{Fe}$ concentration decreased in the kidneys and liver, which is probably due to interference by $\mathrm{Cd}$ in the $\mathrm{Fe}$ uptake mechanism.

The combined therapy procedure can likely increase metal excretion, target specific metal tissues, minimize side effects, and improve compliance. Many studies have now reported 
the high absorption/distribution, long-term efficacy, and safety of DFS and $\mathrm{L}_{1}$ in removing some toxic metal ions and treating $\mathrm{Fe}$ overload in patients with $\beta$-thalassemia major (8-10). After administration of chelators, the $\mathrm{Cd}$ content was reduced. The results show that both chelators (DFS and $\mathrm{L}_{1}$ ) increase the removal of $\mathrm{Cd}$ from the tissues. $\mathrm{L}_{1}$ is able to redistribute $\mathrm{Fe}$ in mammals (17). DFS, by virtue of its small size and the ability to penetrate cells, is efficient in scavenging excess toxic $\mathrm{Cd}(16,18)$. The comparison of single and combined therapy showed that the combined chelation therapy (DFS $+\mathrm{L}_{1}$ ) is more effective in reducing $\mathrm{Cd}$ concentration in all tissues. No effects of $\mathrm{Cd}$ or any of the two treatments $\left(\mathrm{L}_{1}\right.$ or DFS) were observed on WBC, RBC, and $\mathrm{Hb}$ and PLT count showed a decrease in the $\mathrm{Cd}$-exposed rats. $\mathrm{Cd}$ had no effect on these variables in the present study. This can be attributed to the short duration of $\mathrm{Cd}$ exposure. Treatment with DFS and DFS + $\mathrm{L}_{1}$ provided significant recovery in terms of PLT counts.

\section{Conclusion}

Chelation therapy is one of the most effective ways to remove toxic metals from the biological system.

The comparison of the results indicates that the combined therapy (DFS $+\mathrm{L}_{1}$ ) enhanced the removal of $\mathrm{Cd}$ from rat organs considerably. Each of the chelators (DFS and $\mathrm{L}_{1}$ ) has a different target tissue. Therefore, their combination can effectively help the removal $\mathrm{Cd}$ from various tissues. This study might be effective for preliminary testing of the efficacy of chelating agents in the removal of $\mathrm{Cd}$. Therefore, after essential preclinical experiments, the same study can be suggested for human administration.

\section{Acknowledgments}

The authors would like to thank Professor V. Sheibani from Kerman Neuroscience Research Center for his assistance.
Conflict of Interest: None declared.

\section{References}

1. Nordberg GF. Biomarkers of exposure, effects and susceptibility in humans and their application in studies of interactions among metals in China. Toxicol Lett 2010; 192(1):459.

2. Zalups RK, Ahmad S. Molecular handling of cadmium in transporting epithelia. Toxicol Appl Pharmacol 2003; 186(3):163-88.

3. Matovic V, Buha A, Bulat Z, Dukic-Cosic D. Cadmium toxicity revisited: focus on oxidative stress induction and interactions with zinc and magnesium. Arh Hig Rada Toksikol 2011; 62(1):65-76.

4. Malakootian M, Darabi-Fard Z, Amirmahani $\mathrm{N}$, Nasiri A. Evaluation of arsenic, copper, lead, cadmium, and iron concentration in drinking water resources of central and southern Bardsir plain, Iran, in 2014. Journal of Kerman University of Medical Sciences 2015; 22(5): 542-54.

5. Malakootian M, Mobini M, Sharifi I, Haghighi Fard A. Evaluation of corrosion and scaling potential of wells drinking water and aqueducts in rural areas adjacent to Rafsanjan fault in during october to december 2013. Journal of Rafsanjan University of Medical Sciences 2014; 13(3):293-304.

6. Waters RS, Bryden NA, Patterson KY, Veillon C, Anderson RA. EDTA chelation effects on urinary losses of cadmium, calcium, chromium, cobalt, copper, lead, magnesium, and zinc. Biol Trace Elem Res 2001; 83(3):207-21.

7. Kelley C. Cadmium therapeutic agents. Curr Pharm Des 1999; 5(4):229-40.

8. Tandon SK, Prasad S, Singh S. Chelation in metal intoxication: influence of cysteine or $\mathrm{N}$ acetyl cysteine on the efficacy of 2, 3dimercaptopropane-1-sulphonate in the treatment of cadmium toxicity. J Appl Toxicol 2002; 22(1):67-71.

9. Bamonti F, Fulgenzi A, Novembrino C, Ferrero ME. Metal chelation therapy in rheumathoid arthritis: a case report. Successful management of rheumathoid arthritis by metal chelation therapy. Biometals 2011; 24(6):10938.

10. Piga A, Galanello R, Forni GL, Cappellini MD, Origa R, Zappu A, et al. Randomized phase II trial of deferasirox (Exjade, ICL 670), a once-daily, orally administered iron chelator, in comparison to deferoxamine in thalassemia patients with transfusional iron overload. Haematologica 2006; 91(7):873-80. 
11. Amiri A, Fatemi SJ, Fatemi SN. Removal of thallium by combining desferrioxamine and deferiprone chelators in rats. Biometals 2007; 20(2):159-63.

12. Fatemi SJ, Tubafard S, Nadi B. Evaluation of the effect of cadmium on rat organs and investigation of diethyl carbamate as an oral drug in treatment of cadmium toxicity. Med Chem Res 2009; 18(3):179-86.

13. Voskaridou E, Christoulas D, Terpos E. Successful chelation therapy with the combination of deferasirox and deferiprone in a patient with thalassaemia major and persisting sever iron overload after singleagent chelation therapies. Br J Haematol 2011; 154(5):654-6.

14. Hershko C, Konijn AM, Nick HP, Breuer W, Cabatchik ZI, Link G. ICL670A: a new synthetic oral chelator: evaluation in hyper transfused rats with selective radio iron probes of hepatocellular and reticuloendothelial iron stores and in iron-loaded rat heart cell in culture. Blood 2001; 97(4):1115-22.

15. Steinhauser $S$, Heinz U, Bartholoma $M$, Weyhermuller T, Nick H, Hegetschweiler K. Complex formation of ICL670 and related ligands with Fe-III and Fe-II. Berichte der deutschen chemischen Gesellschaft 2004; 21:4177-92.

16. Luparello C, Sirchia R, Longo A. Cadmium as a transcriptional modulator in human cells. Crit Rev Toxicol 2011; 41(1):75-82.

17. Neufeld EJ. Oral chelators deferasirox and deferiprone for transfusional iron overload in thalassemia major: new data, new questions. Blood 2006; 107(9):3436-41.

18. Wan L, Zhang H. Cadmium toxicity: effects on cytoskeleton, vesicular trafficking and cell wall reconstruction. Plant Signal Behav 2012; 7(3):345-8. 